\title{
ОБЗОР КОМПОЗИЦИОННЫХ ПРИНЦИПОВ ГОХУА
}

\section{GUHUA COMPOSITIONAL OVERVIEW}

Lee Fugui

Summary: The composition of Gohua has certain national characteristics that have been formed over millennia. In the process of developing and synthesizing the culture of China with many other cultures, a special form of composition has formed in guhua. The principles on which the composition in guhua is based: main and secondary, illusion and reality, disclosure and completion, sparseness and density, empty space, balance, intersecting, interwoven and overlapping contrast, calligraphic inscription, harmony.

Keywords: Chinese painting, composition, principle.

\section{Ли Фугуй \\ Доцент, Вэйнаньский педагогический университет 2685670024@qq.com}

Аннотация: Композиция гохуа имеет определенные национальные особенности, которые формировались тысячелетиями. В процессе развития и синтеза культуры Китая со множеством других культур в гохуа сформировалась особая форма композиции. Принципы, на основании которых строится композиция в гохуа: главное и второстепенное, иллюзия и реальность, раскрытие и завершение, разреженность и плотность, пустое пространство, равновесие, пересекающийся, переплетающийся и перекрывающийся контраст, каллиграфическая надпись, гармония.

Ключевые слова: китайская живопись, композиция, принцип.

композиции «главное и второстепенное», картина может выглядеть цельной.

2. Иллюзия и реальность. В реальности есть иллюзия, а в иллюзии реальное. Концепция иллюзорного и реального черно-белой каллиграфии в гохуа основана на идеологии Инь и Ян из китайской философии. Реальное - существует, иллюзорное - нет, абсолютной точности не существует, а неточность - существует [7]. Черное и белое порождают друг друга, а также активно применяют реальное и иллюзорное, они порождают на полотне реальное и иллюзорное, создавая впечатление того, что на картине нарисовано то, чего на ней нет. Нарисованное - реально, не нарисованное - иллюзорно. Китайская живопись подчеркивает пустое пространство, и часть картины, которая остается незаполненной и есть иллюзорное, это не значит, что ее не существует, просто иллюзорность заменяет реальность. В «Книге перемен» написано, что Инь и Ян - это Путь, небо - это субстанция Ян, а земля - это субстанция Инь[4]. Сюжет «цветы и птицы» должен иметь реальное и иллюзорное, работа кистью должна иметь реальное и иллюзорное, отношения между важными элементами должны иметь реальное и иллюзорное, каждая часть изображения также должна включать в себя реальное и иллюзорное, и, наконец, каждый росчерк кисти должен иметь реальное и иллюзорное - для того, чтобы картина была живой и ритмичной. Иллюзорное и реальное дополняют друг друга, иллюзорное и реальное могут быть как главным элементом, так и второстепенным.

Пань Тяньшоу сказал, что «рисование - это стремление реального к иллюзорному, а иллюзорного - к реальному»[2]. «Реальное» обычно относится к внешнему виду изображения: это ярко прочерченные контуры, яркий насыщенный цвет, объекты крупные и расположенные 
рядом. «Иллюзорное» обычно означает, что изображение расплывчатое: это светлые оттенки, удаленные и мелкие объекты, а также незаполненные изображением места картины. Если в картине нет «иллюзорной» части, то нет и «реального», а если нет «реального», нет смысла и в «иллюзорном». Кроме того, что композиция в целом должна делиться на реальное и иллюзорное, каждый фрагмент также должен иметь реальное и иллюзорное. Поэтому часто про композицию говорят «в иллюзорном есть реальное, а в реальном - иллюзорное». «Иллюзорное и реальное порождают друг друга, незаполненное пространство на картине также прекрасно». Иллюзорное и реальное являются противоположностями, которые регулируют отношения элементов и вносят изменения в изображение: большое-малое, разреженность-плотность, сосредоточенность-разрозненность, темное-светлое, легкое-тяжелое, сокрытие-подчеркивание. Это проявление отношений реальное-иллюзорное [1].

3. Раскрытие и завершение. Композиция китайской живописи требует раскрытия и завершения. Раскрытие - это высвобождение, завершение - это сдерживание; все это включает в себя раскрытие, продолжение, движение и завершение. «Раскрытие» означает, что люди могут чувствовать динамику и эмоциональное напряжение картины, оно может раскрыть изображение объекта; «завершение» означает закрытие, оно взаимодействует с «раскрытием» и играет координирующую и объединяющую роль в картине. Фактически, обычный способ композиции китайской живописи - это раскрытие и завершение, что включает раскрытие, завершение и их взаимодействие. В частности, разница между «раскрытием» и «завершением» заключается в том, что «раскрытие» означает открытость и эмоциональность, в то время как «завершение» должно быть строгим и «запечатывающим эмоции». Открытость и закрытость портретной и пейзажной живописи сравнительно легко идентифицировать, а в сюжете «цветы и птицы» - сложнее. Причина в том, что композиция сюжета «цветы и птицы» очень разнообразна, и методы различных школ живописи также отличаются: некоторые картины начинают рисовать слева, некоторые начинают рисовать справа, некоторые начинают рисовать сверху, некоторые начинают рисовать снизу и даже с внутренней части картины, а портретная живопись и пейзажная живопись в основном начинают рисовать снизу.

4. Разреженность-плотность. В сюжете «цветы и птицы» «плотность» означает кучность, сосредоточение объектов. «Разреженность» означает свободное и отдельное положение объектов. Эти два качества композиции влияют на общий вид картины. Объекты на картине не должны располагаться слишком плотно или слишком удаленно друг от друга, в плотности существует своя степень разреженности, в разреженности - своя степень плотности, в сосредоточении - разрозненность, в разрозненности - сосредоточение. Разреженность, плотность, сосредоточенность и разрозненность - все это понятия относительные. Без плотности и сосредоточенности невозможно говорить о разреженности и разрозненности. Это так называемое «в разреженностиплотности есть изящество, а в разрозненности-сосредоточенности есть чувство меры», они должны образовывать сильный контраст, тогда картина будет обладать эффектом собранности и свободы, в результате чего возникает чувство ритма, иначе картина станет скучной и неинтересной. Бао Шичэнь в «Ичжоу шуанцзи» писал, что «разреженность может быть неравномерной, а плотность не может иметь разрывов» - это принцип контраста «разреженность-плотность» в гохуа.

Как правило, передний план - плотный, а задний план - разреженный. Если вы рисуете цветы, используйте больше листьев, чтобы подчеркнуть цветок с помощью контраста. При работе с таким контрастом нужно понимать, что плотность не означает отсутствие пробелов, а разреженность - это не пустота. Необходимо обращать внимание на степень плотности, разреженность также должна иметь определенный ритм, тогда картина приобретет живость. Эффект будет только при наличии этого контраста. При создании контраста необходимо одновременно использовать три объекта, например, два плотно расположенных и один - разреженный. При изображении нескольких цветов вместе нужно использовать контраст «разреженность-плотность», чтобы картина получилась красивой: несколько птиц, несколько камней, прожилки на одном листе, узор на одном камне и даже лепестки цветка должны быть расположены по этому принципу. Дай Чуньши сказал: «В плотных местах выражается основной замысел картины, а в разреженных - такое выражение отсутствует. Но необходимо, чтобы в разреженные места также несли некий смысл - в этом и заключается сложность»[6]. Это иллюстрирует связь между разреженностью и плотностью.

5. Пустое пространство. Пустое пространство на полотне - это одна из особенностей гохуа, которая подчеркивает черно-белую палитру картины. Черное и белое, Инь и Ян, порождают друг с друга. Чжуанцзы сказал, что «Инь и Ян взаимодействуют друг с другом, улучшают и поддерживают друг друга»[3]. Такая идеология Инь и Ян отражена в живописи. Наиболее типичным примером является отношение между черным и белым. Это правило композиции. Художники часто говорят «применять белое, но подразумевать черное», что в основном относится к правильному обращению с черным и белым в картине. То есть необходимо уделять внимание не только черной части изображения, но также и пустой части. Много веков художники очень тщательно располагали пустое пространство на картине. Пустое пространство в сюжете «цветы и птицы» должно иметь динамичный контраст. Закон композиции «применять белое, но под- 
разумевать черное» - это, по сути, формирование больших и малых разносторонних треугольников в пустом пространстве изображения. Расположение больших и малых объектов должно быть разным, а расположение пустых участков не может быть симметричным, равномерным, параллельным или располагаться на прямой линии, они должными быть разного размера, располагаться чаще или реже, выше-ниже, ближе-дальше. В большой области черного цвета должен быть небольшой пробел, своеобразная «отдушина».

В композиции гохуа особое внимание уделяется неуловимости, требуется, чтобы пробелы и объекты гармонировали друг с другом, следует избегать произвольного заполнения пространства. Во времена династии Сун художник Жао Цзижань в своем произведении «Хуэйцзун ши эр цзи» впервые предложил «регулировать заполнение пространства». Качество композиции зависит от того, насколько удачно расположены пустые пространства на картине. Они делают объект более заметным, «бимо» выглядит более четким, а цвет более ярким, что создает контраст между иллюзорным пространством и конкретной формой. Пустое пространство обеспечивает пространство для воображения, для домысливания сюжета, и при правильной расстановке оно помогает достичь тонкой художественной концепции. Но пустое пространство здесь - не вакуум, а своего рода «скрытая территория». Оно имеет два значения. Первое - это принцип образности. По изображению на картине мы можем понять, какой предмет олицетворяет это пространство. Второе значение - это принцип отсутствия образности: здесь пустое пространство не представляет какой либо предмет, оно играет роль обрамления или подчеркивает красоту формы[5].

6. Равновесие. Если брать за основу линию центра, то объекты по обеим сторонам от нее будут иметь различную форму, но необходимо создать впечатление, что элементы картины идентичны. Равновесие - это баланс изображения, это не баланс симметрии и качества. В живописи равновесие играет особенно важную роль. Сбалансированная картина отлично удовлетворяет визуальное потребности человека. Когда люди оценивают предметы, им нравится живой, интересный, гармоничный и упорядоченный образ. Им не нравятся образы хаотичные или шаблонные, поэтому равновесие также является ключевым моментом композиции. Во время составления композиции все сюжеты и персонажи на изображении должны иметь определенный порядок и не должны выглядеть слишком аккуратными. Расстояние между двумя объектами и плотность их расположения должны быть организованы в соответствии с визуальными потребностями человека для достижения визуального баланса, что и является равновесием.

Метод симметричной композиции заключается в том, чтобы сделать изображение стабильным, а для того, чтобы нарушить стабильность, изображение объекта в композиции можно слегка сместить, чтобы он находился под небольшим наклоном, и затем сюжет располагается в соответствии со смещением, наклоном, для того чтобы уравновесить изображение. Субъект и объект дополняют друг друга, так что центр тяжести изображения достигает сбалансированного состояния. Это равновесие в композиции.

7. Пересекающийся, переплетающийся и перекрывающийся контраст. В сюжете «цветы и птицы» объекты располагаются плотно и редко, они пересекаются, переплетаются и накладываются друг на друга, так что изображение может быть четко разделено на слои, а цель переплетения и наложения состоит в том, чтобы в изображении прослеживалась последовательность наложения слоев. Например, крупные объекты поддерживают мелкие, а мелкие оттеняют крупные. Принцип переплетения заключается в том, чтобы у объектов появилась связь, взаимодействие, согласованность. Фактически, процесс переплетения также является процессом создания «разреженности - плотности». Хуа Илунь в «Хуа шуо» полагает, что изображение имеет вертикальное и горизонтальное направление, горизонталь разбивает вертикаль, а вертикаль разбивает горизонталь, и таким образом соблюдается баланс. Это показывает, что горизонтальные и вертикальные отношения картины должны быть связаны, при этом акцент делается на «разбитии». Один лист, одна ветвь выглядят монотонно, тогда как два листа и две ветви уже меняют образ, а три или более будут перемежаться, что обогатит композицию и внесет разнообразие. Для создания перемежающегося контраста необходимо создать различные отношения, такие как разреженность и плотность, иллюзия и реальность, насыщенность и бледность. Потому что пересечение чаще фигурирует в сюжете «цветы и птицы». Г-н Гао Гуанхуа предложил использовать два типа пересечения: реальный и иллюзорный. Реальное пересечение означает, что два объекта пересекаются в одной точке. Иллюзорное пересечение означает, что два объекта не пересекаются на бумаге, но если продлить их линии, то они пересекутся в одной точке вне бумаги, то есть пересечение может как отображаться, так и не отображаться на бумаге. Во время зарисовки, до того, как браться за кисть, автор должен иметь четкое представление о порядке действий, в «цветах и птицах» особое внимание уделяется расположению объектов на плоскости изображения, и в основном детально описывается передний план, поэтому необходимо соблюдать последовательность в прорисовке переднего и заднего плана.

8. Согласованность. Относится к взаимодействию и эмоциональной связи человека, фона и предметов на картине. Картина должна иметь последовательное содержание, а объекты сюжета должны поддерживать 
друг друга: каждый из них является самостоятельным объектом, но в то же время между ними должна прослеживаться связь. Во-первых, расположение, облик, ритм, цветы и травы должны отражать движение друг друга: например, цветы и деревья должны тянуться друг к другу, у облаков должно быть извилистое движение. Они должны быть взаимозависимыми и взаимодействовать друг с другом, а тушь, линии, цвета, формы и содержание должны перекликаться друг с другом, создавая взаимодействие, общение и поддержку между человеком, пейзажем и остальными объектами. Во-вторых, выразить связь и поддержку между объектами при помощи оттенков туши. Например, красный цветок поддерживается печатью, объект, написанный тушью, поддерживается каллиграфической надписью, они должны поддерживать друг друга. То есть в рамках композиции даже каллиграфическая надпись и печать выполняют поддержку объектов композиции.

9. Каллиграфическая надпись. Каллиграфическая надпись представляет собой уникальный элемент китайской живописи. Она синтезирует в себе поэзию, книги, картины и гравюры. Она полнее передает особенности китайской живописи. Если каллиграфическая надпись хорошая, она не только освежит, но и подчеркнет красоту и глубину картины. При династии Кун Янши писал в «Шицунь хуа цзуе»: «Каллиграфическая надпись на картинах имеет свое собственное расположение, и она не должна быть неуместной, она заполняет пустое пространство на картине. Если слева нарисована гора, правая сторона свободна, то надпись пишется на правой стороне. Аналогично, если гора нарисована на правой стороне, правая сторона неприкосновенна». Помимо «заполнения пустого пространства» в композиции «цветы и птицы», каллиграфическая надпись также помогает сбалансировать «ци» картины: увеличить, сдержать, сублимировать и так далее. Например, при пересечении и переплетении динамика может оказаться слишком активной, и в таком случае картина получится недостаточно изящной, а если строки каллиграфической надписи получились слишком длинные, это может отрицательно повлиять на изящество изображения. Другим примером является расположение объектов, если комбинация слишком проста, а динамика слишком слаба, мало изысканности, а энергия «ци» получится слишком сильной, это повлияет на красоту картины. В этом случае каллиграфическую надпись можно использовать для «разрыва», что не только обогащает картину, но и усиливает её «изящество». Картина будет эстетически более привлекательной для зрителя.

10. Гармония. Русский художник-экспрессионист Кандинский сказал: «Только через форму и содержание мы можем понять и оценить произведение». Гармоничные и совершенные картины всегда достигают высокой степени единства в содержании и форме. Композиция должна соответствовать теме и стилю произведения, и это принцип, которому все должны следовать, стремясь к красоте. Если есть внутренняя поддержка и сотрудничество между двумя частями или одной частью и всей композицией в целом, это создаст красоту формы, что заставит людей почувствовать гармонию. Еще в древней Греции известный эстетик Пифагор сказал: «Красота - это отражение количественного отношения рационального и идеального, а сущность красоты заключается в гармонии». Прекрасные картины всегда воплощают красоту гармонии, подчеркивая уникальность и художественный шарм. В картинах могухуа «цветы и птицы» доминируют точки, линии, тушь, пробелы, реальное и иллюзорное, при помощи которых они добиваются ощущения единства и гармонии.

\section{ЛИТЕРАТУРА}

1. Ань Лианфа. Учебное пособие по «сие и» могухуа [М] / Ань Лианфа. - Хэфэй: Аньхуэй мэйшу чубаньшэ, 1992. - С.105.

2. Вэй Цихуа. 0 художественных особенностях сюжета «цветы и птицы» в стиле сие и [J]. Академический журнал Танду, 1998. - (1).

3. Лю Цзяньго, Гу Баотянь. Комментарии к Чжуанцзи [М] / Лю Цзяньго, Гу Баотянь. - Чанчунь: Цзилинь Вэньши чубаньшэ, 1993. - С.527

4. У Чжэчжэнь. Тринадцатикнижие [М] / У Чжэчжэнь. - Пекин: Гоцзи Вэньхуа чубаньшэ гунси, 1993. - С.52.

5. Ц Цзян Сюнь. История китайского изобразительного искусства [M] / Цзян Сюнь. - Пекин: Шэнхуо, душу. Книжный магазин Синьчжи Сяньлянь, 2008 . - С. 15 - 16.

6. Чжу Иньжэнь. Записки об известных художниках [М] / Чжу Иньжэнь. - Наньнин: Гуаньси мэйшу чубаньшэ, 2004. - С.62.

7. Юнь Шупин, Наньтянь Хуаба, Ю Аньчжэнь. Сборник статей о живописи. 3-е издание. Пекин: Жэньминь мэйшу чубаньшэ, 1960. - С.175.

(с) Ли Фугуй (2685670024@qq.com). 